- основными методами и приёмами организации данного факультативного курса являются: объяснительно-иллюстративный; практический; исследовательский.

1. Душина, И. В. Методика и технология обучения географии : пособие для учителей и студентов / И. В. Душина. - Москва : ООО Издательство «Астрель», 2004. - 218 с. : ил. - Текст непосредственный;

2. Запрудский, Н. И. Организация факультативного обучения в 11-летней школе / Н. И. Запрудский. - Мн. : Зорны верасень, 2008. -215 с. - Текст непосредственный;

3. Румянцева, С. Е. Внеклассная работа и развитие личности учащихся / С. Е. Румянцева - Текст непосредственный // География в школе. - 2000. - № 6. - С. 55 - 57.;

4. Тишкевич, О. В. Формы, методы и средства проведения факультативного занятия / О.В. Тишкевич. - Текст электронный. - URL: https://nsportal.ru/blog/shkola/obshcheshkolnayatematika/all/2013/07/23/formy-metody-i-sredstva-provedeniya (дата обращения: 26.03.2021). - Режим доступа: для зарегистрир. пользователей.

\title{
Вельдина Ю.В. \\ Преимущества и недостатки использования онлайн-технологий при обучении иностранному языку
}

Пензенский государственный технологический университет (Россия, Пенза)

doi: 10.18411/lj-04-2021-138

\section{Аннотация}

Изучение иностранного языка с помощью онлайн-технологий приобретает всё большую популярность. В данной статье рассматриваются преимущества и недостатки использования в процессе обучения иностранному языку современных онлайнтехнологий, а также анализируются способы и результаты их применения.

Ключевые слова: онлайн-технология, иностранный язык, процесс обучения.

\section{Abstract}

Learning a foreign language with the help of online technologies is becoming increasingly popular. This article deals with the advantages and disadvantages of using modern online technologies in the foreign language educative process and analyses the ways and results of their use.

Keywords: online technology, foreign language, the educative process

Пандемия коронавируса (COVID-19) в корне изменила многие аспекты жизни. От нее пострадали все сферы государства, однако больше всего потерь понесли система здравоохранения и экономика, и мир сейчас стоит на грани глобального экономического кризиса. Необходимость социального дистанцирования и минимальных контактов для предотвращения распространения инфекции изменили способы коммуникации и взаимодействия между людьми. Альтернативные средства коммуникации, в частности Интернет, заменил собой традиционные методы. Интернетуслуги, например, онлайн-конференции через платформы Zoom или Skype, a также онлайн-обучение через платформы Moodle стали неотъемлимой частью делового и учебного процесса.

В связи с этим возник вопрос о том, каким же образом система образования в целом, и система высшего образования, в частности, будет адаптироваться с поставленной задачей, а именно, обучением студентов. В настоящее время большинство вузов переведено полностью на дистанционный формат обучения, либо процесс строиться на смешанном формате (часть занятий, преимущество лекции, 
проводятся дистанционно, а практически занятия проходят в стенах вуза). В связи с этим встает вопрос и поиске новых методов, которые могли бы в такой-то мере облегчить процесс обучения в сложившихся условиях.

В данной статье нами будут рассмотрены современные онлайн-технологии, которые позволять в какой-то степени снизить риски заражения COVID-19, а также разнообразить процесс обучения по предмету «Иностранный язык» в высшем учебном заведении.

Но что на самом деле такое «онлайн-технологии»? В дидактике при обучении иностранным языкам под онлайн-технологиями понимаются все средства обучения, которые служат проводниками информации [5]. Поэтому в последнее время в методике появляются все новые и новые термины, такие как «новые медиа средства», «цифровые средства массовой информации», «электронное обучение», «обучение через Интернет», «виртуальное обучение» или «Web 2.0» [6].

Однако, на наш взгляд, достаточно четкое определение принадлежит Фройденштейну, который рассматривает онлайн-технологии в обучении иностранному языку как результат технологического развития, которые в виде компьютеров, смартфонов и планшетных компьютеров - с помощью Интернета - обеспечивают передачу информации и способствуют интерактивному обучению [3].

Согласно этому термину, средства обучения включают в себя Интернет, смартфоны, пояснительные видеоматериалы, электронную почту, WhatsApp или другие учебные приложения, планшеты, социальные сети, такие как блоги, вики, Twitter, Facebook, PowerPoint, подкасты и др. С помощью облачных решений, таких как Microsoft Teams или Dropbox, пользователи могут обмениваться и совместно использовать информацию или редактировать один и тот же документ одновременно. К наиболее значимым онлайн-технологиям помимо вышеперечисленных следует отнести следующие: Calaméo, Gloster, LearningApps, Mindmeister, Podcasts, Quizlet, Voki, Voxopop, Wordle, социальные сервисы Данные технологии представляют собой очень удобные бесплатные сервисы для публикации различных файлов, текстов, фото, видео, звуковых файлов, графики, ссылок и др., создание интерактивных заданий для учебновоспитательного процесса в разных режимах («Пазлы», «Найди пару», «Найди соответствие», «Установи последовательность», «Викторина с выбором правильного ответа», «Кроссворд») и др. [2, С.24].

В настоящее время онлайн-технологии могут быть использованы различными способами. Например, изображения, видео или звукозаписи могут быть использованы в качестве введения в новую тему для изучения. YouTube, смартфон или онлайн-курсы в Интернете способствуют самостоятельному обучению. Учебные продукты можно легко сохранять и обмениваться ими друг с другом. Электронную почту, чаты или социальные сети можно использовать непосредственно при проведении занятий или дома для развития всех видов речевой деятельности.

Онлайн-технологии готовят изучающих язык к требованиям общества и экономики. Интернет позволяет всем участникам образовательного процесса общаться друг с другом, независимо от их местонахождения, и совместно работать над заданиями. Кроме того, данные технологии позволяют организовать индивидуальное обучение. Студенты могут совместно определять содержание и темп обучения и адаптировать его к своим собственным потребностям и уровням. Таким образом, иногда рассматриваются различные виды обучения и включаются различные виды речевой деятельности, такие как чтение, аудирование и говорение [6]. И последнее, но не менее важное, это способствует развитию самостоятельности в обучении.

Несмотря на эту важную роль, немногие эмпирические исследования показывают, что использование онлайн-технологий не способствует значительному улучшению успеваемости в изучении языка по сравнению с традиционным обучением 
[3]. Однако они могут выполнять свою роль только в том случае, если: 1. высшие учебные заведения будут иметь технические и финансовые ресурсы; 2. преподаватели будут открыты для инноваций и готовы постоянно совершенствовать свои навыки и использовать современные онлайн-технологии в процессе обучения; 3. студенты будут иметь возможность использовать онлайн-технологии в соответствии со своими потребностями и способностями.

Каких же целей можно достичь с помощью онлайн-технологий? Как говорилось выше, онлайн-технологии позволяют обучающимся определять свои собственные цели, содержание и темп обучения. Однако не всему можно научиться с помощью них. Тактильные и двигательные навыки, а также социальные навыки трудно преподавать с помощью новых средств массовой информации. Основы эмпатии и навыки урегулирования конфликтов, безусловно, можно преподавать с помощью новых медиа, но самому, этому умению можно обучиться только через взаимодействие с людьми [6].

Конечно, есть и недостатки, связанные с использованием онлайн-технологий в образовательном процессе. Чувства, запахи, мимика и жесты не могут быть переданы с помощью онлайн-технологий. Однако эти аспекты не менее важны, чем чистое изучение языка. Групповые динамические эффекты отсутствуют без социального присутствия различных персонажей в помещении и, следовательно, зачастую, без социальных взаимодействий и контактов [4].

Кроме того, онлайн-технологии не очень хорошо подходят для сложных тем. Они предполагают наличие базовых знаний и навыков, которые не могут быть реализованы теми, кто не привык к обучению. Избыток и поток информации иногда вводит в заблуждение. В полезное время становится все труднее найти адекватные и правильные источники.

Таким образом, современные тенденции порождают новые формы обучения. Будущие тенденции, в свою очередь, приведут к появлению еще более новых форм обучения, о которых мы даже не знаем сегодня. Важно постоянно быть в курсе развития современных средств, которые можно использовать в процессе обучения иностранному языку. Для того чтобы положительные результаты были достигнуты, высшие учебные заведения должны установить рамочные условия, а преподаватели должны быть открыты для изменений. Технические средства должны поддерживать цели обучения, которые ставятся на конкретном уроке. В лучшем случае студенты должны быть вовлечены в разработку и проведение занятий с помощью онлайнтехнологий. Таким образом, повышается мотивация и развивается самостоятельность в обучении. Современные онлайн-технологии в обучении иностранному языку также дают возможность иногда узнать о чем-то лучше, чем преподаватель, и, таким образом, могут быть взаимно обучены друг у друга. Иногда это укрепляет хорошую культуру обсуждения, что полезно не только для изучения языка, но и для общества в целом. Чтобы уменьшить негативные аспекты, следует проводить тщательную интеграцию новых средств информации. Предпочтение, возможно, следует отдавать «смешанному обучению». Обучение было и остается процессом построения отношений. Для того чтобы так и дальше продолжалось, онлайн-технологии должны быть не «экономистами», а помощниками. Следовательно, использование онлайн-технологий в процессе обучения иностранному языку в высшей школе имеет больше плюсов, чем минусов, так как их дидактические возможности достаточно широки. Среди основных следует назвать: 1. Интерактивность (интерактивное использование созданных учебных модулей и программ). 2. Функциональная совместимость (совмещение информации из различных электронных источников.). 3. Взаимозаменяемость (легкое и гибкое адаптирование содержания учебных модулей и их использование в любых контекстах). 4. Доступность (доступное получение необходимой информации через любые 
программные устройства). 5. Ситуативность (направленность всех интерактивных упражнений на внутреннюю необходимость речевой деятельности). 6. Мотивированность (стремление улучшить свои имеющиеся знания) [1, С.7].

1. Вельдина Ю.В. Об использование интернет-сервиса «Deutsche Welle» в образовательном процессе // Человек, общество, образование: состояние, проблемы и пути их решения: сборник трудов Международной научно-практической конференции, 27мая 2020г., Пенза, ПензГТУ. - Прага: Vedecko vydavatelske centrum «Sociosfera-CZ», 2020. - С. 78.

2. Гусарова Ю.В. Технологии Веб 2.0 как способ формирования социокультурной компетенции у студентов неязыкового вуза // Азимут научных исследований: Педагогика и Психология. - Номер: 1 (10). - 2015. - C. 24-26.

3. Freudenstein R. Unterrichtsmittel und Medien: Überblick in Lehr- und Lernmaterialien und Unterrichtsmedien. In K.-R. Bausch, H. Christ, \& H.-J. Krum, Handbuch Fremdsprachenunterricht. Tübingen: Francke., 2007. - S. 395-399.

4. Rösler D. E-Learning Fremdsprachen: eine kritische Einführung. Stauffenburg. - 2007.

5. Storch G. Medien. In G. Storch, Deutsch als Fremdsprache - Eine Didaktik. - München: Fink, 2008. - S. 271-282.

6. Wicht G. E-Learning und Neue Medien in der betrieblichen Aus- und Weiterbildung. In C. Negri, Angewandte Psychologie für die Personalentwicklung. - Berlin: Springer, 2010. - S. 170-187.

\section{Воробьева Е.Е., Морозова Н.А., Антонов А.С. \\ Новые технологии обучения в образовательном процессе высшего медицинского образования}

ФГБОУ ВО "Пензенский государственный университет" (Россия, Пенза)

doi: 10.18411/lj-04-2021-139

\section{Аннотация}

Современное развитие комплекса учебно-методических материалов, внедрение всевозможных технических средств в образовательном процессе, а также методов и форм их применения для усовершенствования функционирования специалистов учреждений высшей школы оказало существенное влияние на педагогический процесс в высших учебных заведениях и на жизнь общества в целом.

Следует отметить, что педагогический процесс в медицинском вузе имеет особую отличительную черту. Широкое применение активных и практикоориентированных форм обучения в реализации дисциплин в медицинских вузах объясняется тем, что студентам необходимо приобрести не только определенные знания, но и научиться их применять в конкретной ситуации на практике.

Необходимо помнить, что главное в процессе обучения - активная деятельность студента и его желание стать профессионалом в своей деятельности, что возможно при усилении мотивации к обучению и поисковой активности.

Ключевые слова: педагогическая технология, дидактическая система, кейсметод, эффективность преподавания, медицинское образование, ситуационная задача.

\section{Abstract}

Modern development of the complex of educational and methodological materials, introduction of various technical means in the educational process, as well as methods and forms of their use with the aim of improvement of specialist's activity in universities has had a significant impact on the pedagogical process in higher education institutions as well as on society life in general. It should be noted that the pedagogical process in a medical university has a special distinctive feature. The widespread use of active and practice-oriented forms of education in the implementation of disciplines in medical universities are explained by the fact that students should acquire not only theoretical knowledge, they should learn how to 